\title{
Can Health Economics aid decision making in healthcare innovation in academia?
}

\author{
Bo Lu, Jennifer L Martin, Michael P Craven, Stephen P Morgan* \\ MATCH for Multidisciplinary Assessment of Technology Centre for Health \\ Department of Electrical and Electrical Engineering \\ University of Nottingham \\ United Kingdom \\ Email: steve.morgan@nottingham.ac.uk \\ *Corresponding author
}

\begin{abstract}
Health economics is extensively used by reimbursement agencies to make decisions on whether to adopt new medical technologies. It is also used by the healthcare industry as an aid to decision making during product development. This paper proposes that academic healthcare technology transfer could also benefit from adopting health economics.

The study investigated the knowledge and attitudes of academic staff involved in developing and transferring healthcare technologies. The participants had little or no prior knowledge of health economics; however, the majority reported that this method had the potential to aid development and commercialisation. The innovations developed by the workshop attendees and their commercialisation plans were of a type that could potentially benefit from cost-effectiveness calculations.

Health Economics has the potential to make a valuable contribution to academic healthcare innovation. Research is required to develop this method further and ensure that it can be successfully applied in academia.
\end{abstract}

Keywords: Health Economics; healthcare technology; academic innovation; technology transfer; cost-effectiveness analysis; decision making; stage gate model.

Biographical notes: Bo Lu is a Research Fellow of the Multidisciplinary Assessment of Technology Centre for Healthcare, University of Nottingham, UK. Her main research interest are in health economic evaluation tool development and applications.

Jennifer Martin is a Research Fellow of the Multidisciplinary Assessment of Technology Centre for Healthcare, University of Nottingham, UK. Her main research interests are in the application of Human Factors methods to the development and design of medical devices.

Michael P Craven is a Senior Research Fellow of the Multidisciplinary Assessment of Technology Centre for Healthcare, University of Nottingham, UK. He is engaged with applied projects in collaboration with MATCH's industry and health service partners, primarily in the area of medical device evaluation. He is currently working closely with the NHS National Innovation Centre and Centre for Evidence-based Purchasing. Dr.

Copyright @ 200x Inderscience Enterprises Ltd. 
Craven has additional experience in electronic engineering and computer science teaching and research, including design of communication aids, surgical simulation devices \& software, and collaborative virtual environments.

Stephen P Morgan PhD is Professor of Biomedical Engineering. Since 1992 he has been researching novel optical techniques for imaging and spectroscopy of tissue. In 1998 he was awarded a prestigious EPSRC Advanced Fellowship to perform research in biomedical optics. His research is in two main application areas; firstly, the development of novel optical techniques for applications in regenerative medicine. This research has involved applying techniques such as ultrasound modulated optical tomography, polarized light imaging and machine vision to 3D tissue growth in bioreactors. Secondly, he has developed novel optical techniques for monitoring blood flow in the microcirculation. He is also active in the area of technology transfer and works closely with the UK National Health Service on methods for assessing the value of healthcare technologies.

\section{Introduction}

There is a growing consensus across the world that innovation and technology play a key role in ensuring long-term sustainable economic growth. These issues become even more important in times of economic crisis. In Europe, extensive financial and policy support has been provided to bring innovations to market across the whole of the European Union (EU) and the individual European nations (CEC, 2009). In the USA, a series of strategies have been initiated to maintain its competitive status in innovation (Bendis and Byler, 2009). In the UK, it is a long-term policy of the government to build an innovation nation', to encourage knowledge transfer and to increase the link between universities and business (DIUS, 2008). Innovation by academic institutions plays an important role in achieving these government ambitions.

A current global economic downturn compels academic researchers and research funders to place even greater emphasis on the potential social and economic impact of innovation to the nation. The response to this by the Research Councils within the UK (RCUK), one of the main UK academic research funders, has been to stipulate that an impact statement is included in any funding application. Taking the Engineering and Physical Sciences Research Council (EPSRC) as an example (EPSRC, 2009a, b), funding applicants are asked to set out the potential impact of their proposed research in terms of: economic potential; healthcare and quality of life (QoL) improvements; new skills or the contribution to the advancement of knowledge. Although scientific quality of the research is still the primary criterion for funding, research councils are increasingly focusing on the potential impact of innovations. Issues such as these, combined with the importance academia now places on commercialising innovations, means that effective methods are required, which allow both researchers and funders to demonstrate and evaluate the impact of the innovations developed by academic institutions. 
Of all the industry sectors, healthcare is the fastest growing and plays a significant role in society as well as the economy. The World Health Organization (WHO) has called for innovative health technologies with the aim of identifying and evaluating innovative medical devices to make quality healthcare accessible to the whole world. The EU is launching a joint programme from 2010 to 2013 on improving health technology assessment cooperation among European countries. A particular strength of the UK is research into world-leading healthcare technologies, which are highly innovative and knowledge-based (TSB, 2009). The National Health Service (NHS), the main healthcare service provider and principal healthcare technology purchaser in the UK, has taken strategic actions to promote innovation and adoption. As Darzi recently identified, 'Innovation in the NHS isn't just a luxury: it's a necessity if we want to have a health service that provides high quality care for patients' ever evolving needs" (Darzi, 2009). One recent initiative is the National Innovation Centre (NIC), launched as part of the NHS Institute for Innovation and Improvement, aims to encourage innovation and speed up adoption of innovation into the NHS. The UK Government also provides a range of programmes to encourage innovation by providing investment aimed at health research (TSB, 2009).

One criticism that has historically been levied at the UK is that it is good at research but poor at its exploitation (Lambert, 2003; Sainsbury, 2007). However, recent initiatives from central government, national and regional organisations and universities have improved this situation. According to the Sainsbury Review (Sainsbury, 2007), which is based on metrics such as attracting external investment and producing spin-out companies, UK universities are now performing at an equivalent level in technology transfer as their top US counterparts. The Government has developed a number of schemes to encourage the technology transfer and increase the impact of academic innovations (DIUS, 2008). For example, the Higher Education Innovation Fund programme (Sainsbury, 2007) was set up in 2001 with the aim of encouraging technology transfer by academia and a number of initiatives are organised by the RCUK including the knowledge transfer portal, launched in February 2009 (BBSRC, 2009), which provides full support and guidance for university-business interaction activities. There is substantial evidence, therefore, of the increasingly important role that universities are playing in the national and local economy. The key challenge for successful technology transfer is identifying potentially profitable and commercially successful technologies. There is a need for methods and tools to enable better decisions to be made when identifying technologies that are likely to have the greatest impact.

In this paper, we consider innovation by academic institutions in the area of healthcare technology. We propose that a health economic approach can be effectively used to assess the potential value of a healthcare technology at an early stage in the development process. We suggest that this method can be used by a variety of stakeholders, including technology transfer officers and research funders, to identify those technologies that will have the greatest impact, from a clinical cost-effectiveness perspective. Health economics is a readily available technique for healthcare technology 
evaluation and it has been widely applied by healthcare authorities and the healthcare industry, however it is a relatively new approach for academia.

Health economics provides an effective method for evaluating the costeffectiveness of healthcare technology from the healthcare purchaser perspective. This type of economic evaluation is becoming increasingly popular worldwide when making decisions on whether to adopt new healthcare technologies (Kobelt, 2002). In the UK, the NHS routinely applies cost effectiveness analysis for health technology assessment of treatments. This type of analysis is carried out by: the National Institute for Health and Clinical Excellence (NICE) of England and Wales; Quality Improvement Scotland; and the Department of Health, Social Service and Public Safety Northern Ireland. Health economics has also been successfully used as a marketing tool by the healthcare technology industry.

In recent years, as well as using it to demonstrate the value of mature products to healthcare providers, the healthcare industry applying health economics as early as possible during the product lifecycle. The aim of this approach is to improve the development decisions made and increase the likelihood of the product being commercially successful (Craven et al., 2009; Cosh et al. 2007). We propose that this concept could also be applied to the assessment of the value of healthcare technology innovations developed by academia, for example at the early stages of either a research funding application or during technology transfer.

The need for wider education in Health Technology Assessment amongst nonspecialists is evidenced by its relevance to training aimed at clinical engineers and biomedical technicians (Menon 1993, Elder and Corrin, 1995, Gilly, 2007). Inventors of mobile devices and software with clinical applications also need to be aware of HTA processes (Craven, 2006). HTA is beginning to find its way into university engineering courses.

However, developing Health Economic Models is a complex process and as a result, formal health economic tools are often only employed by professional health economists on behalf of healthcare authorities or large pharmaceutical and medical device companies. There is a need, therefore for a simple and easy to use costeffectiveness analysis tool which can be effectively applied by companies with fewer resources as well as healthcare innovation purchasers.

An early stage tool to aid decision making based on health economics has recently been developed by the UK-based EPSRC funded Multidisciplinary Assessment of Technology Centre for Healthcare (MATCH). The tool has been designed for people that have little or no experience of health economics. It is aimed at the healthcare technology industry and the NHS as a means of accelerating the adoption of innovative technology.

The aim of this paper is to investigate how health economics may contribute to the evaluation of healthcare innovations developed in academia. We present an overview of the theory of Health Economics and the background to the development of the $\mathrm{MATCH}$ health economic tool. A secondary aim is to investigate how this approach may 
be used by academic researchers during the development or technology transfer of healthcare innovations by means of a questionnaire study.

\section{Application of Health Economics to healthcare innovation in academia}

\subsection{Health Economics and a Health Economic Evaluation Tool}

\section{What is Health Economics?}

The study of health economics arises from the confliction between the finite resources available and the demanding requirements from the public for better healthcare. Health economics therefore deals with issues of reasonable resource allocation, making choices about competing interventions with the aim of maximising value-for-money. A health economic evaluation compares costs and benefits of two (or more) healthcare interventions (Fox-Rushby and Cairns, 2005). Thus, economic evaluation compares one intervention relative to another or several alternatives in terms of cost and benefit differences. There are different types of economic evaluation methodologies designed to assess the cost-effectiveness of different interventions, e.g. cost-minimization analysis, cost-consequence analysis, cost-effectiveness analysis, cost-utility analysis and costbenefit analysis (Kobelt, 2002). Cost-utility analysis is currently employed by NICE for healthcare technology appraisal (NICE, 2008). It also forms the theoretical basis of the MATCH health economic evaluation tool.

In health economic evaluation, the costs involved in the treatment are measured in terms of money, while the outcome of the healthcare intervention can be measured in different ways within different contexts for different comparative aims. The most frequently used measure of the health outcome is the quality-adjusted-life-year (QALY), which measures the medical consequences in terms of quantity (life years) and quality of life (utility) gained through a treatment, i.e. QALY = Number of years spent in a particular health state $\mathrm{x}$ the Utility of that health state. The utility is a numerical measure of a particular health state between 0 and 1, where 0 represents dead and 1 is perfect health (Kobelt, 2002).

The result of a health economic evaluation is represented by the incremental cost effectiveness ratio (ICER), i.e. the differences in costs divided by the differences between the effects of different clinical interventions. For a cost-utility analysis, the clinical effect is measured using the QALY and the ICER is therefore expressed in the following form;

$$
\begin{aligned}
\text { ICER } & =\frac{\text { Cost of New Treatment }- \text { Cost of Old Treatment }}{\text { Effect of New Treatment }- \text { Effect of Old Treatment }} \\
& =\frac{\text { Differencein Costs }(\triangle \text { Cost })}{\text { Differencein Effects }(\triangle Q A L Y)}
\end{aligned}
$$


The ICER can be displayed on a cost-effectiveness plane as shown in Figure 1 which represents the difference in outcome on the horizontal axis and the difference in cost on the vertical axis. The cost-effectiveness plane shows four types of outcomes arising from the incremental differences between the new and incumbent treatments. Quadrant I represents the situation when the new treatment should be rejected as it is less effective and more expensive. Quadrant III represents the opposite situation; it should be accepted, as the new treatment is more effective and less expensive. Quadrants II and IV represent situations where there is a trade-off between costs and benefits. Due to the preference of the healthcare decision makers for more effective treatments, more focus is given to Quadrant II in which the innovative healthcare technology brings more benefits but costs more money than the existing situation. Decisions on whether the improvements in outcome are worth the additional cost can then be made based on a willingness-to-pay (WTP) threshold. WTP represents the maximum level of acceptance of the healthcare purchasers for the extra costs caused by the new technologies. If the ICER lies below the WTP it has a higher probability of being accepted, for example point A in Figure 1. If the ICER lies above the WTP it will be rejected e.g. point B in Figure 1. In the UK, NICE generally sets the WTP threshold at $£ 25 \mathrm{~K}-£ 30 \mathrm{~K} / \mathrm{QALY}$ (NICE, 2008).

The aim of a health economic evaluation is to aid decision making based on a variety of data, which is analyzed on the basis of a health economic model. The most frequently used modeling methodologies in health economics are a decision tree model and a Markov model (Kobelt, 2002; Fox-Rushby and Cairns, 2005). A decision tree model depicts the possible events and outcomes of the treatment and is considered to be the simplest economic model, while the Markov model is more powerful at modeling chronic conditions with relapse symptoms. The MATCH health economic evaluation tool is based on the decision tree model.

\section{The MATCH Health Economic Evaluation Tool}

MATCH has developed a health economic evaluation tool using Microsoft Excel, which is designed for use by people who are not expert in health economics. The tool is based on cost-utility analysis which follows the NICE 'reference case' economic evaluation approach (NICE, 2008). A binary decision tree model is employed to compare the differences in costs and benefits between the innovative healthcare technology and the alternative, as shown in Figure 2. Under more complicated situations, a more complicated decision tree model could be constructed with more branches followed by more than two health outcomes. But for the purpose of simplifying the problem and considering the broader spectrum of users of the tool, the MATCH tool employs a simple binary decision tree structure.

Reading from left to right in Figure 2, the decision tree starts from the square decision node, and the two branches originating from the decision node represent the innovative and existing healthcare technologies. The green circle decision node represents the possible actions for each condition. The decision tree ends at the red 
triangle end node. The tool considers two possible outcomes with the treatment, i.e. healthy or not healthy. The health status is expressed with utility values and the final health benefits are measured with QALYs.

Figure 3 displays a screenshot of the tool developed within Microsoft Excel. The tool is described in more detail elsewhere (Craven et al., 2009). The top left shows the cost-effectiveness plane displaying the ICER and WTP threshold. The decision tree is shown on the right hand side and data is input in the centre panel. Scroll bars (bottom left, figure 3) can be used to investigate the sensitivity of different parameters. The tool also provides a breakeven analysis, which is designed for the healthcare manufacturer to anticipate the potential profitability (screen not shown here).

The data needed for the tool include the direct/indirect costs, the utility of the final health states after the treatment and the probability of each event. This information can be obtained through clinical trial, expert opinion or a literature review. At an early stage of product development, in the absence of established data, a developer could simply use a best estimate.

Figure 1 The Cost-effectiveness plane. Point A is cost effective, while point B is not

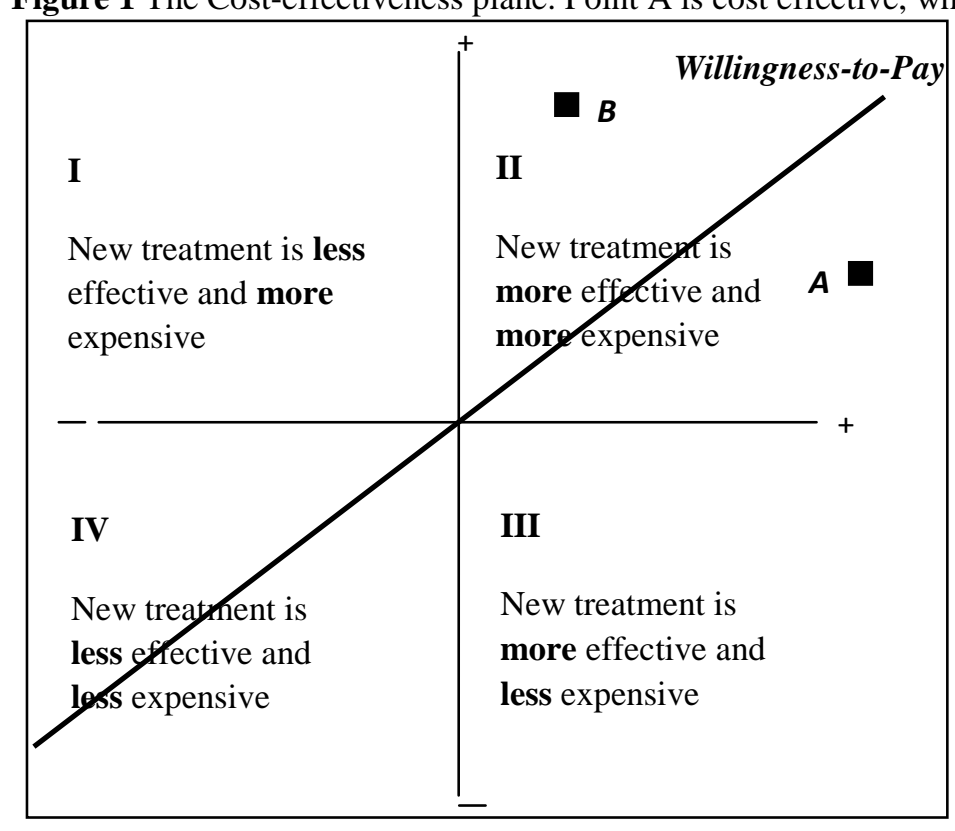




\section{Author}

Figure 2 Decision tree structure of the MATCH Health Economic Evaluation Tool

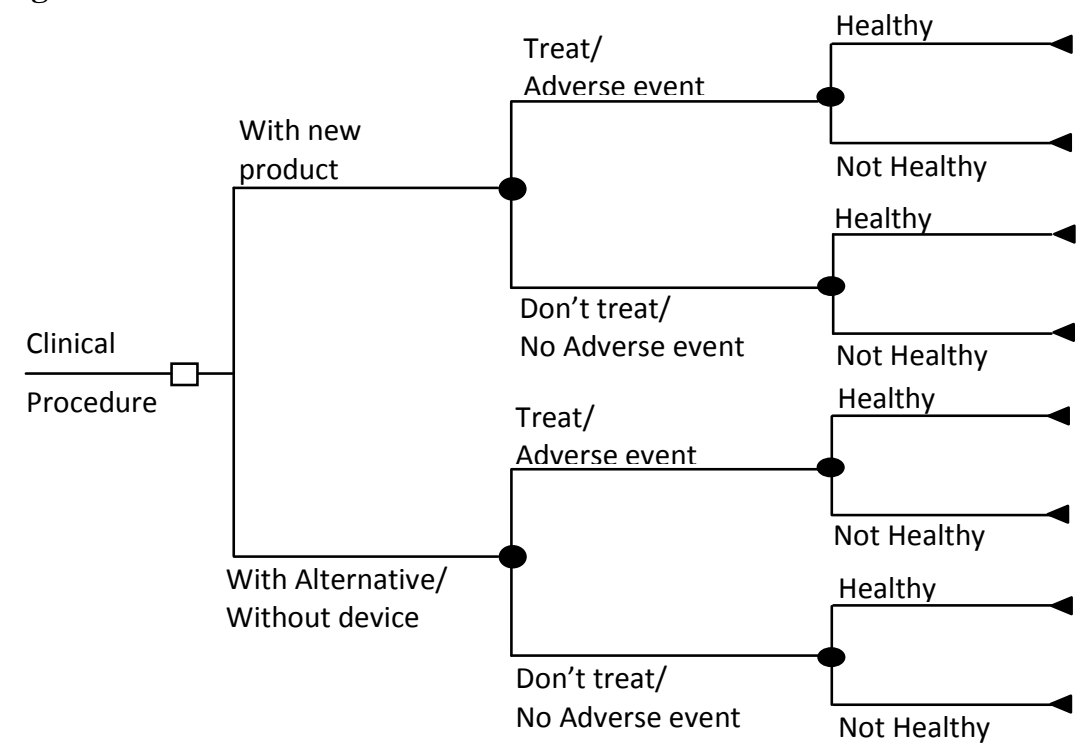

Figure 3 The MATCH Health Economic Evaluation tool 


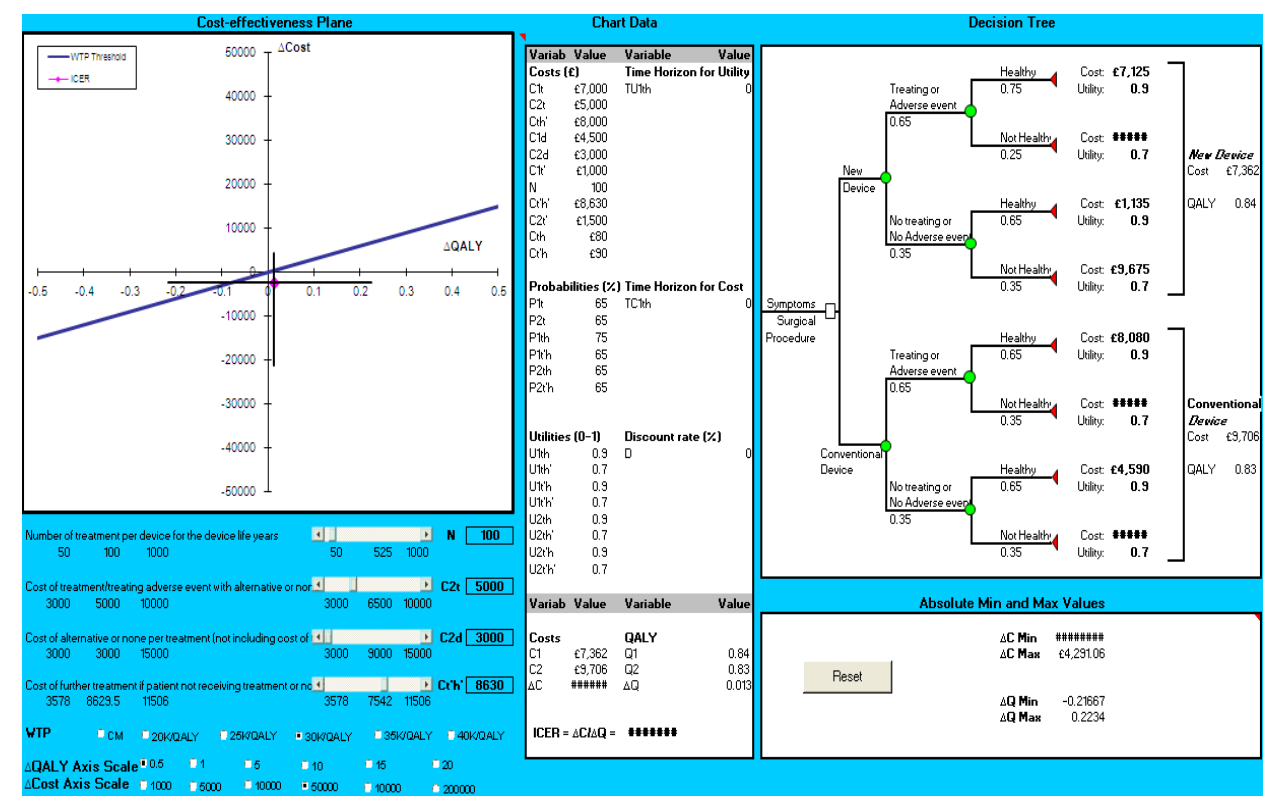

\subsection{Stage gate model}

A stage gate model (Cooper, 2009) is frequently used by industry in the product development process and has been suggested as an appropriate model for medical device development (Pietzsch et al, 2009). This takes a product from concept through to market. At specific points in the development process ('gates'), decisions are made on whether to continue or cease with the development. At different stages tools can be used to aid decisions. An example is shown in Figure 4 where a business product passes through the stages from the initial concept until launch. Healthcare technologies are usually assessed using health economic approaches at a late stage in the development process, e.g. Stage 4 of the post-development testing stage in Figure 4. Within MATCH we have worked with industry to embed this type of assessment approach earlier in the development process (Craven et al., 2009; Cosh et al., 2007), e.g. Stage 2 of the pre-development investigation stage in Figure 4. Clearly at an early stage in the development process clinical trials of a product will not have taken place, however, it should be possible to estimate the performance of a product in order to understand its potential cost-effectiveness. For example if an optimistic estimate of the performance is made and the product is still not shown to be cost-effective then questions about future investment should be raised.

We propose that a similar stage gate model can be constructed to describe the healthcare technology development process in academia and its subsequent technology transfer. As shown in Figure 5, the process is divided into 6 stages, i.e. concept, research development (research funding application), research commercialisation development 
(technology transfer funding application), industrial development, market, and reimbursement. The process shown in Figure 5 has a similar form to that shown in Figure 4 but with the focus on showing the stages of embedding the health economic approach into the academic innovation development process.

The first stage shows an initial idea for a healthcare innovation, a decision then needs to be made as to whether a research funding application should be made (gate 1 of Figure 5). After funding and its associated research, a decision then needs to be made within the academic institution as to whether to attempt to commercialise the product (gate 2 of Figure 5). If a positive decision is taken, then funding can be sought to transfer the technology (Lambert, 2003; Sainsbury, 2007). This could be done in several ways, e.g. by obtaining industrial investment, by setting up a collaborative research partnership, by licensing the product to the companies or by formation of a spin out company. Successful transfer of the technology into an industrial environment then results in the product development process following a similar stage gate model as described in Figure 4. An additional reimbursement stage is added, which is where the decision is made by healthcare providers on whether to adopt the technology.

At each gate in the product development process a health economic tool can be used to predict what the likely adoption decision of a healthcare provider would be. Clearly at an early stage the data supplied to the model will be less accurate, e.g. carrying out cost-effectiveness analysis with estimated data at 'gate 1' of Figure 5, but this will improve as the product moves through the development process, e.g. in-house trial data could be used at the 'gate 2' and clinical trial data could be used at 'gate 4' of Figure 5.

There are several advantages to this approach. Firstly it allows both academics and technology transfer staff to assess which innovations are likely to have the greatest impact on healthcare. This is often useful when technology transfer offices are inundated with innovations. Secondly, as previously discussed, there is an increasing demand from research funders for applicants to demonstrate the value and impact of new technologies and this approach offers the potential to achieve this. Finally a health economic approach can be used to fulfill the demand from potential investors for technology transfer staff to demonstrate the value of the innovation.

Figure 4 A generic stage gate model depicting the business process from idea to launch

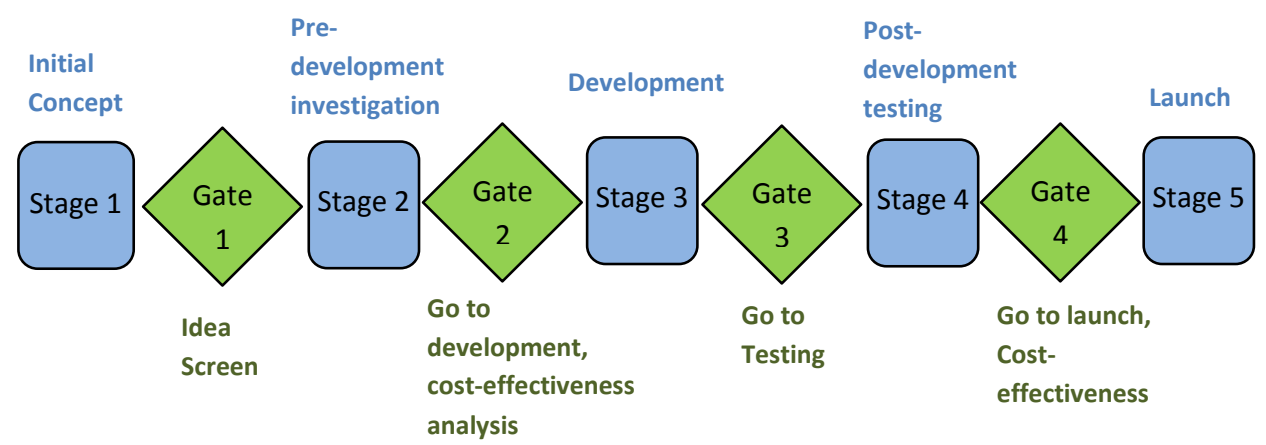


Figure 5 Academic innovation development stage gate model

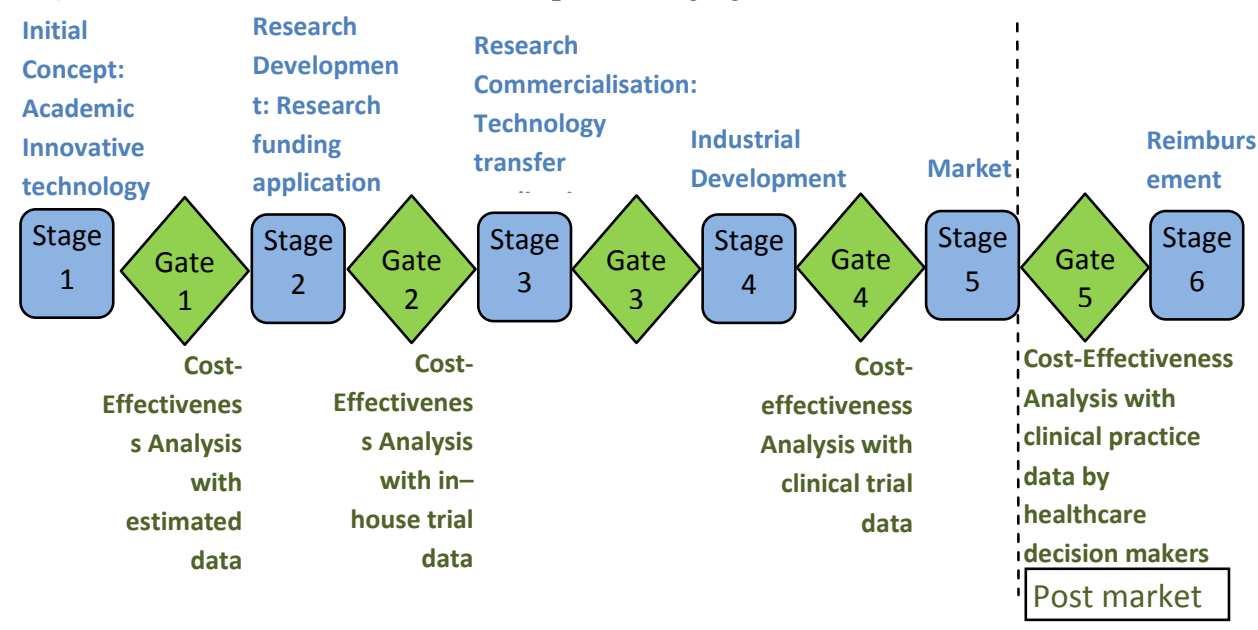

\subsection{Case Study Examples}

The MATCH HE tool has been successfully applied to the development of a number of real medical devices. This was in collaboration with the NHS National Innovation Centre who are assisting Small and Medium Enterprises, many of which are university spin-out companies, to self-assess the value of their innovations at an early stage in the R\&D process. Examples of novel devices included an optical blood glucose meter and a dynamic oxygen therapy system.

The findings from these case studies demonstrated a number of benefits for the product developer. It helped them identify data requirements essential for building the value proposition for their innovation. Crucially, this data included not only costs, but the outcomes measures that the health provider would focus on when making a purchasing decision. More generally, by using the tool, the innovators were stimulated to formally articulate the positioning of their device in the patient pathway; it also allowed the innovator to directly compare its benefits in relation to the existing alternative technology i.e. their competitor. Use of the tool also encouraged 'stage-gate thinking' by identifying the data that would be required to make informed decisions at future points in the development process, a process that has been shown to benefit new product development (Cooper and Kleinschmidt, 1991; Page, 1993).

For a full description of these early-stage device evaluations see Craven et al., 2009. 


\section{Survey of decision making in healthcare technology development in academia}

\subsection{Health Economics Workshop}

A workshop on Health Economics and the MATCH Health Economic tool was held at the University of Nottingham on the 19th June 2009. The aims of this workshop were twofold. Firstly, to introduce the theory of health economics and the MATCH HE tool to academics working on healthcare innovations. Secondly, to investigate the nature of healthcare innovation with academia in order to determine to what extent health economics could contribute to this.

The workshop was advertised via email to all staff at the University as 'Assessing and demonstrating the value of your Healthcare Technology'. It was suggested that it may be relevant to academics, researchers and research students developing innovative healthcare technologies and technology transfer officers. A total of 28 staff attended the workshop, which lasted for approximately 3 hours.

The workshop, which was conducted by the authors, began by introducing health economics and describing how this method was applied in the UK. Some key concepts in cost-effectiveness analysis were presented in detail such as utility, QALY, and the cost-effectiveness plane. Participants were also given details of additional sources where information on data collection could be found.

Following the health economics presentation, the MATCH HE tool was described and then demonstrated using a real case example from the area of orthopaedic technology, and the data required for the calculations identified. All the attendees were then provided with the opportunity to perform the case study example themselves by installing the tool software on their own laptop computers. The authors were on hand throughout to provide any assistance that the attendees required.

Following the workshop all attendees were asked to complete a questionnaire containing a mixture of both open and closed questions. The questionnaire covered a number of topics regarding the attendees' healthcare related research interests including:

- Background information about the attendees

- The types of healthcare innovations they were involved in and the potential impact of these

- Their previous knowledge and experience of health economics

- Their current plans for commercialising and demonstrating the value of their innovations

- Their priorities when initiating innovative product development

- Their views on the priorities of research funders

- Their views on the MATCH HE tool

In addition, the questionnaire also asked the attendees to provide feedback on the workshop. 


\subsection{Results of Questionnaire Study}

The main results are described below following the order of the questions in the questionnaire.

Question 1: Please briefly describe your role within the university.

Question 2: Please briefly describe your healthcare related research interests.

Of the 28 attendees, nineteen participants returned a completed questionnaire. The majority of the respondents held academic teaching positions at the university such as professor (1), reader (6) and lecturer (3). A number of people with research only positions also attended including both postgraduate students (2) and post-doctoral researchers (4) and a research nurse (1). The non-academic attendees consisted of knowledge transfer specialists (2). All the respondents have healthcare research related background.

Question 3: Please select the potential impact of your research on healthcare.

The most common response to this question was that it would be 'more effective than products currently on market' with the majority of the attendees (13/19) selecting this option (Figure 6). Eleven of the respondents believed that their innovation would offer an improvement over current clinical practice, either a radical improvement (5) or an incremental one (6). Only 4 participants reported that their innovation would be cheaper than the products currently on the market. Other reported potential impacts included changing the clinical pathway (4) and improving patient safety (6).

Question 4: Is there a plan to commercialise your academic innovation?

Question 5: How do you plan to transfer your knowledge?

The majority (13/19) of the respondents expressed that they planned to commercialise their research outcomes. When asked about how they were planning to transfer the knowledge of their healthcare innovation, 12 of the 19 respondents reported that they were planning on licensing the product to a company (Figure 7) and 7 reported that they were considering starting up a spin-out company. Unsurprisingly academic publications were also a popular way of transferring knowledge (11 respondents).

Question 6: Before this workshop, what would you consider to be your knowledge of health economics?

Of the 19 respondents, five people reported that their knowledge of health economics was 'medium' and 7 people as 'low'. The other 7 people reported that their previous knowledge of health economics was non-existent. None of the respondents reported that their health economics knowledge was 'expert' or 'high'.

Question 7: How do you normally demonstrate the value of your work to research funders and other investors? 
Just one person reported that they normally performed a cost-effectiveness calculation when seeking to demonstrate the value of their work to funders or investors (Figure 8). The most popular way of demonstrating the value of an innovation was by quoting published data (15) followed by conducting clinical trials (7) and obtaining support from key opinion leaders (6).

Question 8: How do you rate the following factors in influencing the decisions of your main research funders?

The participants were asked to list their primary and secondary research funders and rate what they believed to be the priorities at funding assessment of their research funders. As the respondents were all from an engineering and science background, the main research funders for the participants were EPSRC (11) followed by EU (6). Other research funders were the Department of Health, the NHS National Institute for Health Research, research councils, and other public organisations. Only one participant reported that their research was supported by a company. Due to lack of funding application experiences, one participant missed this question. Of the 18 respondents, six people reported having one research funder only.

Table 1 and Table 2 show the participants' perceptions of the priorities of their primary and secondary research funders. It can be seen from this data that the participants believed that a number of issues were considered during the application process. There was a high degree of agreement between the respondents that the most important factor was the 'scientific quality of the proposed work' with 16 out of 18 respondents rating this as either extremely or very important to their primary research funder and 11 out of 12 for the secondary. The 'social impact on healthcare and quality of life improvement' was also viewed by the respondents as a high priority of research funders, being rated as either extremely or very important by $15 / 18$ for the primary research funder and 10/12 for the secondary. The economic impact on the UK or EU was also recognised by participants. Of all the respondents, the primary funders were UK-based organisations and 14 of the 18 respondents rated the 'economic impact on UK' as either extremely or very important. 6 respondents reported that the EU was their secondary funder and all of them rated 'economic impact on EU' as extremely important.

Question 9: What are your decision-making priorities when initiating innovative product development?

Like research funders' priorities, a large number of factors influence the academic community to innovate in healthcare (Table 3). Seventeen participants gave full responses to this question. For healthcare innovation, all of the respondents thought meeting clinical/patient needs are extremely or very important. Enthusiasm of a clinical expert for the product is also extremely or very important (14/17). Other factors like the availability of research funding are still the main driver of academic innovation with 15 out of 17 respondents rating this as extremely or very important. Other factors such as scientific interest, the opinion of industrial partners, commercial opportunities and potential for short term success were seen as less important. 
Question 10: How would you rate the MATCH HE tool for each of the following aspects?

Eighteen participants provided their initial responses to the MATCH HE tool. The tool was rated as easily learnt by 16 of the 18 respondents, 17 of the respondents stated that the output from the tool was clear with 14 reporting that they understood the output. The breakeven analysis option in the tool was reported as useful by 14 of the 18 participants.

Figure 6 'Please select the potential impact of your research on healthcare (tick all that apply).' $(\mathrm{n}=19)$

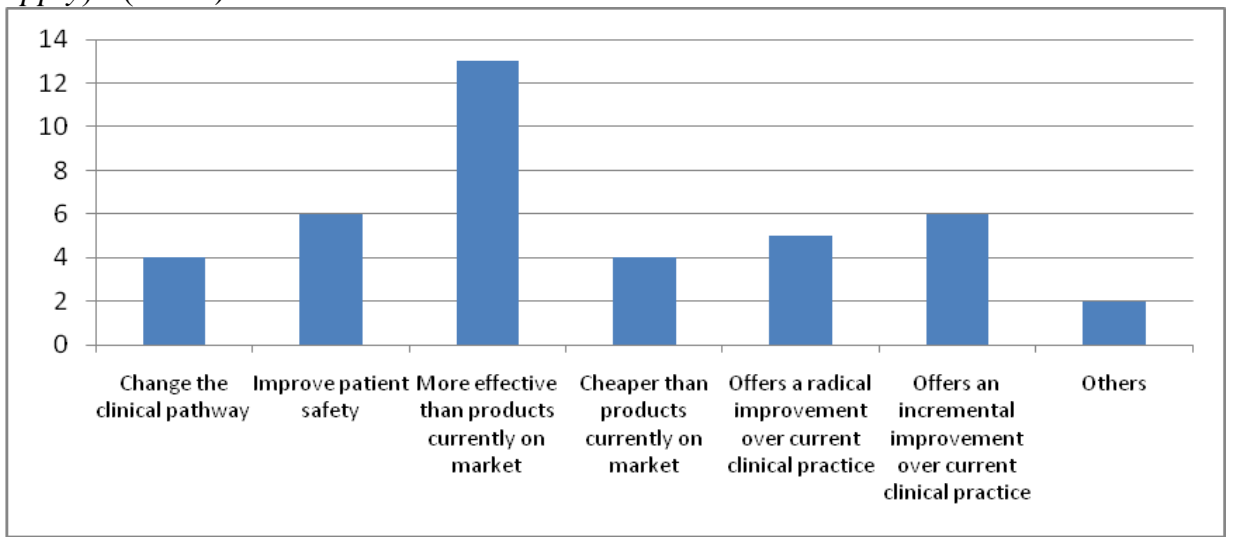

Figure 7 'How do you plan to transfer your knowledge (tick all that apply)?' (n=19)

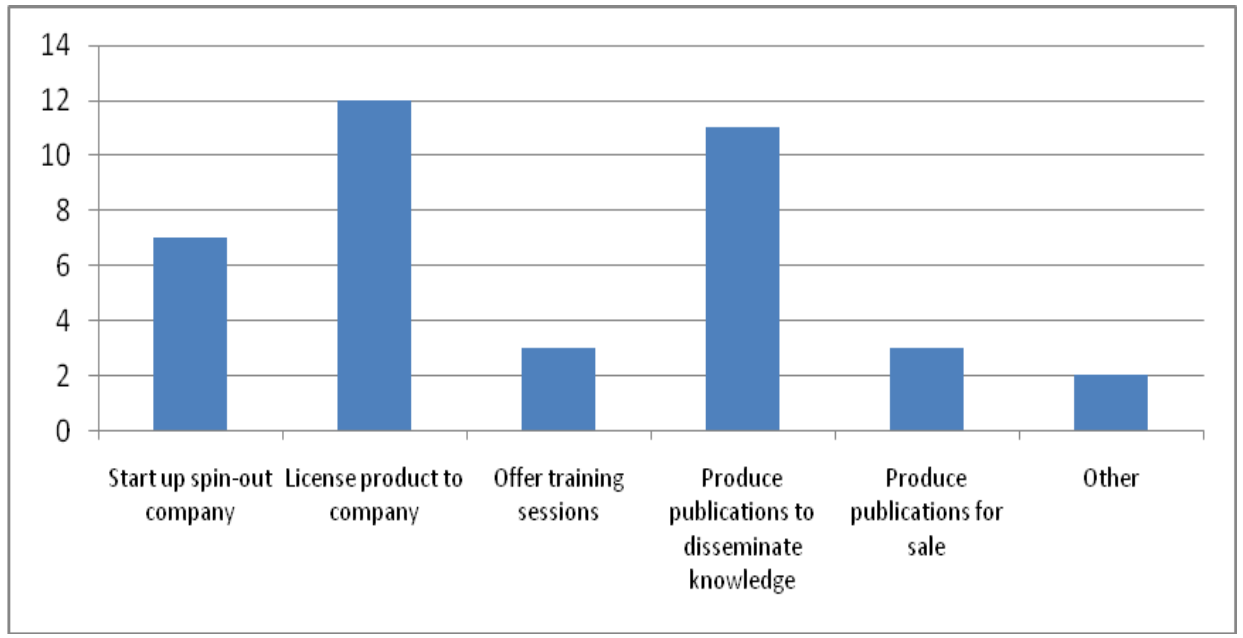




\section{Author}

Figure 8 'How do you normally demonstrate the value of your work to research funders and other investors? (tick all that apply)' $(\mathrm{n}=19)$

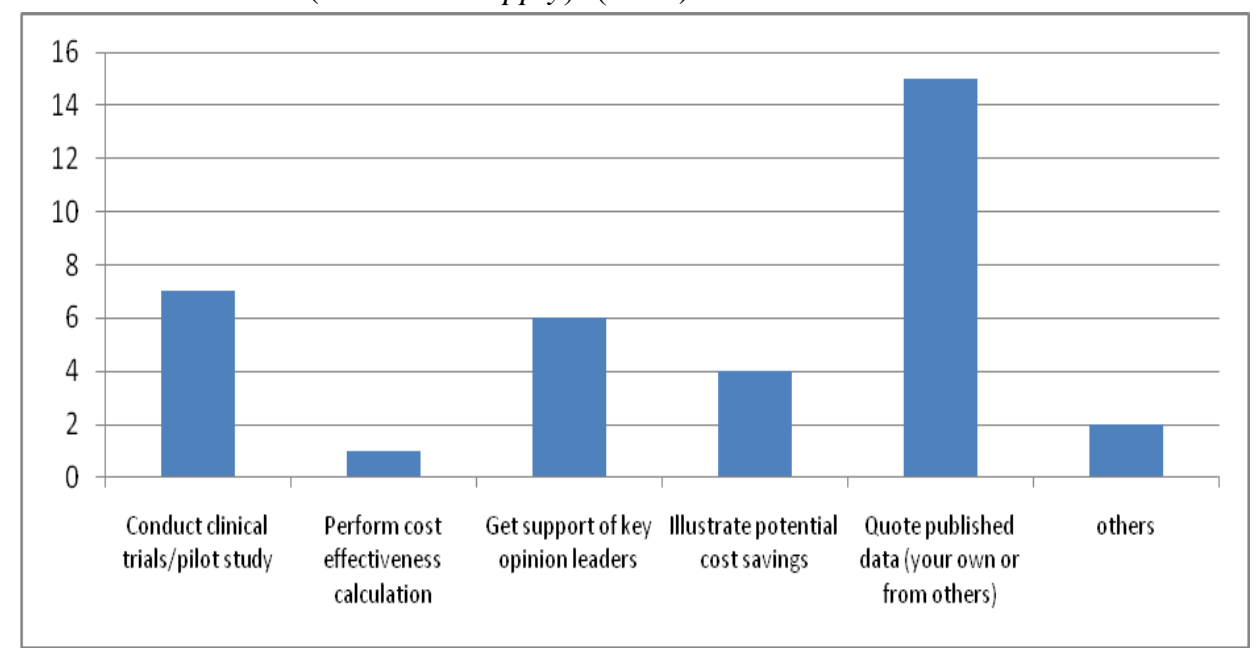

Table 1 Priorities of primary funder for funding assessment $(n=18)$

\begin{tabular}{|c|c|c|c|c|c|}
\hline & $\begin{array}{l}\text { Extremely } \\
\text { important }\end{array}$ & $\begin{array}{c}\text { Very } \\
\text { important }\end{array}$ & $\begin{array}{c}\text { Moderately } \\
\text { important }\end{array}$ & $\begin{array}{c}\text { Slightly } \\
\text { important }\end{array}$ & $\begin{array}{l}\text { Not at all } \\
\text { important }\end{array}$ \\
\hline $\begin{array}{l}\text { Scientific quality of } \\
\text { proposed work }\end{array}$ & 9 & 7 & 2 & 0 & 0 \\
\hline $\begin{array}{l}\text { Your own academic } \\
\text { reputation }\end{array}$ & 3 & 14 & 0 & 1 & 0 \\
\hline $\begin{array}{l}\text { Social impact on healthcare } \\
\text { and quality of life } \\
\text { improvement }\end{array}$ & 6 & 9 & 3 & 0 & 0 \\
\hline Economic impact on UK & 9 & 5 & 3 & 1 & 0 \\
\hline Economic impact on EU & 3 & 5 & 5 & 4 & 1 \\
\hline $\begin{array}{l}\text { Potential for short term } \\
\text { benefits (3-5yrs) }\end{array}$ & 2 & 5 & 8 & 2 & 1 \\
\hline
\end{tabular}


Table 2 Priorities of secondary funder for funding assessment $(n=12)$

\begin{tabular}{lccccc}
\hline & $\begin{array}{c}\text { Extremely } \\
\text { important }\end{array}$ & $\begin{array}{c}\text { Very } \\
\text { important }\end{array}$ & $\begin{array}{c}\text { Moderately } \\
\text { important }\end{array}$ & $\begin{array}{c}\text { Slightly } \\
\text { important }\end{array}$ & $\begin{array}{c}\text { Not at all } \\
\text { important }\end{array}$ \\
\hline $\begin{array}{l}\text { Scientific quality of } \\
\text { proposed work }\end{array}$ & 6 & 5 & 1 & 0 & 0 \\
$\begin{array}{l}\text { Your own academic } \\
\text { reputation }\end{array}$ & 4 & 4 & 3 & 1 & 0 \\
$\begin{array}{l}\text { Social impact on healthcare } \\
\text { and quality of life }\end{array}$ & 7 & 3 & 2 & 0 & 0 \\
$\begin{array}{l}\text { improvement } \\
\text { Economic impact on UK }\end{array}$ & 4 & 2 & 5 & & 0 \\
$\begin{array}{l}\text { Economic impact on EU } \\
\begin{array}{l}\text { Potential for short term } \\
\text { benefits (3-5yrs) }\end{array}\end{array}$ & 8 & 1 & 1 & 2 & 0 \\
\hline
\end{tabular}

Table 3 "What are your decision-making priorities when initiating innovative product development?" (n=17)

\begin{tabular}{|c|c|c|c|c|c|}
\hline & $\begin{array}{l}\text { Extremely } \\
\text { important }\end{array}$ & $\begin{array}{c}\text { Very } \\
\text { important }\end{array}$ & $\begin{array}{l}\text { Moderately } \\
\text { important }\end{array}$ & $\begin{array}{l}\text { Slightly } \\
\text { important }\end{array}$ & $\begin{array}{l}\text { Not at all } \\
\text { important }\end{array}$ \\
\hline $\begin{array}{l}\text { Opinion of Industrial } \\
\text { partners }\end{array}$ & 4 & 9 & 3 & 0 & 1 \\
\hline Commercial opportunities & 3 & 6 & 6 & 2 & 0 \\
\hline $\begin{array}{l}\text { Availability of research } \\
\text { funding }\end{array}$ & 10 & 5 & 2 & 0 & 0 \\
\hline $\begin{array}{l}\text { Enthusiasm of clinical } \\
\text { expert for the product }\end{array}$ & 7 & 8 & 2 & 0 & 0 \\
\hline Scientific interest & 7 & 6 & 3 & 1 & 0 \\
\hline $\begin{array}{l}\text { Potential for short term } \\
\text { success }\end{array}$ & 1 & 4 & 4 & 6 & 2 \\
\hline $\begin{array}{l}\text { Opportunity to further } \\
\text { career reputation }\end{array}$ & 3 & 4 & 6 & 3 & 1 \\
\hline $\begin{array}{l}\text { Meeting clinical/patient } \\
\text { needs }\end{array}$ & 8 & 9 & 0 & 0 & 0 \\
\hline
\end{tabular}

\section{Discussion}

The objective of this paper is to propose that a health economics based method can aid early decision making in healthcare technology development in academia. A secondary 
objective is to investigate how this approach might fit into academic innovation and the response of the academic community to it.

A variety of academic staff with a range of research experiences attended the Health Economics workshop. As the workshop was entitled 'Assessing and demonstrating the value of your Healthcare Technology', this suggests that the commercialisation of research innovations is a priority to a variety of academic staff and not restricted to particular specialties or grades of staff. Our position, described earlier in this paper, that commercialisation of healthcare innovations is a priority for UK universities, is also supported by the attendance of a number of knowledge transfer specialists.

Previous knowledge of health economics amongst the attendees was relatively low, which supports our hypothesis that health economics is a relatively new area to academic staff involved in the development of healthcare technologies. Only one person out of the 19 attendees had previous experience of health economic assessment.

The results of the questionnaire, as well as the informal responses of the participants during the workshop, show that this group of academics was enthusiastic about potentially integrating health economics into their research assessment. The positive responses to this new technique were likely to be due to some extent to the backgrounds of the audience. The majority of the attendees had science and engineering backgrounds and, therefore, can be assumed to be highly numerate, meaning that they were likely to find the theory and concepts behind Heath Economic modeling relatively straightforward.

The questionnaire results provide support for our hypothesis that health economics has a valuable contribution to make to academic healthcare innovation. Most of the innovations described by the respondents were focused on the effectiveness part of the cost-effectiveness analysis, with only a small number reporting that their innovation would be cheaper than products on the market (it is a reasonable assumption that the rest will be more expensive). This suggests that for most healthcare innovations some sort of cost-effectiveness calculation will be needed to persuade purchasers, investors or funders that the additional patient benefits are worth the increased cost of the innovation. As stated earlier, health economics is increasingly being used by these stakeholders to aid purchasing and investment decisions.

In terms of commercialisation plans, the majority of the respondents reported that they were planning on either licensing their product to a company or starting a spinout company. In these instances cost-effectiveness analysis would be valuable in assisting decision making during commercial product development, further supporting our assertion that health economics can benefit healthcare innovations from the very early stages, and throughout development. The fact that the majority of the attendees reported that the ability to perform a breakeven analysis would be useful is further evidence in support of our hypothesis that health economics methods can benefit academic innovators. The academics in our study reported that quoting published data is still the main method of demonstrating the value of the academic innovation to research funders and that they believe that the scientific quality is still the primary priority for research 
funders. However, they also reported that social and economic impact is growing in importance for research funding assessment and this further supports for the need for an effective technique to demonstrate and evaluate the trade-off of the innovation between cost and effectiveness.

The respondents reported that there are a large number of priorities for their research funders and that they believe that research funders place a lot of importance on the social impact of healthcare and quality of life improvements when funding research. This suggests that academic innovators have to focus on a number of different issues when preparing funding applications, which is very challenging. The provision of a relatively easy to learn and accessible tool could assist academic innovators in performing early stage health economic calculations. The MATCH HE tool has been designed to carry out basic cost-effectiveness analysis for the people who have little or no experience in health economics (Craven et al., 2009). The questionnaire data indicates that the MATCH HE tool and its outputs are readily understandable and usable by academic healthcare innovators.

The questionnaire study was an exploratory investigation, with a small and selfselected sample from one institution, and as such we must be wary of generalising the results from this study to the wider academic community. In addition, we acknowledge that the University of Nottingham is affiliated with a large NHS acute trust and as a result, healthcare innovation is likely to be a particularly important research theme for this institution.

However this work backs up the findings of our previous case studies with SMEs, many of which are university spin-outs, that demonstrated the value of such an evaluation tool in informing new product development by encouraging 'stage-gate thinking'. Furthermore, postgraduate courses in engineering departments are increasingly stressing the need to consider not only the technology that makes up a device, but also the part the device will play in the patient pathway, and how it will be assessed by health providers.

\section{Conclusions}

We have proposed a method of aiding decision-making for new healthcare technologies developed within academia. This is based upon applying health economics at an early stage in the product development process. This offers both academic and technology transfer staff the opportunity to assess which technologies are likely to provide the greatest impact on healthcare. It is also a useful approach when demonstrating the value of the technology to research funders and potential investors.

A working knowledge of health economics should benefit academic researchers working on the design of healthcare innovations. The next stage of this work will be validating the use of the MATCH HE tool by academics in the laboratory i.e. at a stage in the $R \& D$ process that is prior to formation of a spin-out company. 
In addition, we will further develop the MATCH HE tool, and its training, to ensure that it fully meets the needs of users with little prior knowledge of health technology assessment.

\section{Acknowledgements}

The authors acknowledge support of this work through the MATCH Program (EPSRC Grant GR/S29874/01), although the views expressed are entirely their own.

\section{References}

BBSRC News (2009). 'Research Councils UK launch Knowledge Transfer Portal'.

Available at:

http://www.bbsrc.ac.uk/media/news/2009/090225_launch_knowledge_transfer_portal.ht $\underline{\mathrm{ml}}$.

Bendis, R. and Byler, E. (2009) Creating a National Innovation Framework: Building a Public-Private Support System to Encourage Innovation. Science Progress of Innovation America. Available at: http://www.scienceprogress.org/2009/04/creating-a-nationalinnovation-framework/.

Commission of the European Communities (CEC) (2009). Communication from the Commission to the European Parliament, the Council, the European Economic and Social Committee and the Committee of the Regions, Reviewing Community innovation policy in a changing world: Reviewing Community innovation policy in a changing world. Brussels. http://www.era.gv.at.

Cooper, R.G. (2009) 'How companies are reinventing their idea-to-launch methodologies'. Research-Technology Management, Vol. 52, No. 2, pp.47-57.

Cooper, R.G., and Kleinschmidt, E.J. (1991) 'New product processes at leading industrial firms'. Industrial Marketing Management, Vol. 20, No. 2, pp 137-147.

Cosh, E., Girling, A., Lilford, R., McAteer, H. and Young, T. (2007) 'Investing in new medical technologies: A decision framework'. Journal of Commercial Biotechnology, Vol. 13, No. 4, pp.263-271.

Craven, M. P. (2006) Routes and requirements for realizing pervasive medical devices. In: Bardram J. E., Mihailidis A., Wan D. (Eds.), Pervasive computing in healthcare. CRC Press (Taylor \& Francis Group), Boca Raton, Fla; London. ISBN 084933621X.

Craven, M.P., Morgan, S.P., Crowe, J.A. and Lu, B. (2009) 'Deploying a spreadsheet tool for early economic value assessment of medical device innovations with healthcare decision makers'. Journal of Management \& Marketing in Healthcare, Vol. 2, No. 3, pp.1-15.

Darzi, A. (2009) 'Why innovation matters today'. BMJ, Vol. 339, b2970. 
Department for Innovation, Universities \& Skills, March (DIUS) (2008a). Innovation Nation. London: The Stationery Office.

Department of Innovation, University \& Skills (DIUS) (2008b). Implementing "the Race to the Top": Lord Sainsbury's review of Government's science and innovation policies. London: The Stationery Office.

Elder, S. Corrin, N. (1995) 'Biomedical engineering's role in hospital health technology assessment', IEEE Engineering in Medicine and Biology Society, 17th Annual Conference, vol. 1, $711-712$.

EPSRC (2009a). New measures to improve peer review. EPSRC letter Connect, Issue 70. Available at: http://www.epsrc.ac.uk/Publications/Connect/default.htm.

EPSRC (2009b). Impact plan advice. EPSRC letter Connect, Issue 73. Available at: http://www.epsrc.ac.uk/Publications/Connect/default.htm.

Gilly, H. (2007) 'Current Status of Clinical Engineering, Health Care Engineering and Health Care Technology Assessment in Austria', Proc. International Federation for Medical and Biological Engineering (IFMBE), 11th Mediterranean Conference on Medical and Biomedical Engineering and Computing 2007, Volume 16, Part 29, 10701073.

Fox-Rushby, J. and Cairns, J., (2005) Economic Evaluation. Maidenhead: Open University Press.

Kobelt, G. (2002) Health Economics: An Introduction to Economic Evaluation. London: Office of Health Economics.

Lambert, R. (2003). Lambert Review of Business-University Collaboration. London: HM Treasury.

Lord Sainsbury of Turville (2007). The Race to the Top: A Review of Government Science and Innovation Policies. London: HM Treasury.

Menon, D. (1993) 'Technology assessment and biomedical engineering education, Medical and Biological Engineering and Computing, Special feature: Healthcare Technology Assessment, Vol. 31, No. 1, HTA33-HTA36.

NICE (2008). Guide to the Methods of Technology Appraisal. [pdf] London: NICE.

Page, A.L. (1993) 'Assessing New Product Development Practices and Performance: Establishing Crucial Norms'. Journal of Product Innovation Management, vol. 10, No. 4, pp 273-290.

Pietzsch, J. B., Shluzas, L. A., Paté-Cornell, M. E., Yock, P. G. And Linehan, J. H. (2009) 'Stage-gate processes for the development of medical devices'. Journal of Medical Devices, vol. 3, 021004-1-15

Technology Strategy Board (TSB) (2009). Medicine and Healthcare Strategy 2009-2012. Available at: http://www.innovateuk.org/_assets/pdf/Corporatepublications/MedicinesHealthcareStrategy.pdf 